\title{
Dangerous game: preferential predation on baboons by African wild dogs in Mana Pools National Park, Zimbabwe
}

\author{
Esther van der Meer ${ }^{\mathrm{a}, *}$, Nick Lyon ${ }^{\mathrm{b}}$, Thomas Mutonhori ${ }^{\mathrm{a}, \mathrm{c}}$, \\ Roseline Mandisodza-Chikerema ${ }^{c}$ and Peter Blinston ${ }^{\mathrm{a}}$ \\ ${ }^{\text {a }}$ Painted Dog Conservation, P.O. Box 72, Dete, Zimbabwe \\ ${ }^{\mathrm{b}}$ BBC Natural History Unit, P.O. Box 194, Bristol, United Kingdom \\ ${ }^{\mathrm{c}}$ Zimbabwe Parks and Wildlife Management Authority, P.O. Box CY140, Harare, \\ Zimbabwe \\ *Corresponding author's e-mail address: esthervdmeer@gmail.com \\ Received 6 September 2018; initial decision 23 September 2018; \\ revised 12 November 2018; accepted 12 November 2018; \\ published online 14 December 2018
}

\begin{abstract}
When selecting prey, carnivores optimise energy gained when consuming prey against energy spent when pursuing and subduing prey. Additionally, predators seem to preferentially predate on prey which presents a low risk of injury. When defending itself against predators, baboons (Papio spp.) can inflict serious injury and cause mortality. Although part of Africa's large carnivores' diet, predation on baboons is usually avoided. We investigated prey selection patterns of African wild dogs (Lycaon pictus) in Mana Pools National Park, Zimbabwe. Based on direct and indirect observations and analyses of faecal samples, we show that baboons form a substantial part of the African wild dog diet and were more frequently predated on than would be expected based on availability. Predation on baboons did not vary over baboon sex or age classes but was affected by seasonality. This is the first study to describe a preference for predation on this unusual prey species.
\end{abstract}

\section{Keywords}

African wild dog, Lycaon pictus, Chacma baboon, Papio ursinus, prey selection, dangerous prey, hunting injury. 


\section{Introduction}

For most mammalian predators prey size increases with body size, with small carnivores $(<20 \mathrm{~kg})$ predating on prey smaller than themselves and large carnivores $(>20 \mathrm{~kg}$ ) predating on prey their own size or larger (Carbone et al., 1999, 2007). Although a shift from small to large prey increases energy intake, pursuing and subduing large prey requires more energy and therefore results in an increase in energy expenditure. Consequently, carnivores have developed several behavioural and ecological strategies to optimise energy intake and expenditure (Carbone et al., 2007). African wild dogs (Lycaon pictus) are social coursing predators with a body mass of ca. $25 \mathrm{~kg}$ (Carbone et al., 2007 (S1)). By hunting cooperatively in packs the species is able to reduce foraging costs and pursue and subdue prey much larger than their own body size (Creel \& Creel, 2002; Radloff \& du Toit, 2004). African wild dogs generally predate on antelopes within a body mass range of 16$32 \mathrm{~kg}$ and 120-140 kg (Hayward et al., 2006a). Preferred prey species in east and southern Africa are greater kudu (Tragelaphus strepsiceros), Thomson's gazelle (Gazella thomsonii), impala (Aepyceros melampus) and bushbuck (Tragelaphus scriptus) (Hayward et al., 2006a).

African wild dogs hunt daily, at dusk and dawn or when sufficient moonlight is available (Estes \& Goddard, 1967; Creel \& Creel, 2002). The species hunts opportunistically using sight, aided by auditory and olfactory cues (Estes \& Goddard, 1967; Creel \& Creel, 2002). Hunting strategy varies with habitat type, with long-distance pursuits of prey by multiple individuals in a pack in open grassland habitats (Estes \& Goddard, 1967), and several individual hunting attempts, which result in low individual kill rates but high pack feeding rates as prey is shared, in mixed woodland habitat (Hubel et al., 2016). As cursorial hunters, African wild dogs show a tendency to predate on the slowest individuals, e.g. young animals or animals in poor body condition (Fitzgibbon \& Fanshawe, 1989; Pole et al., 2004).

While hunting, carnivores have more at stake than energetic expenditure and hunting success alone: they can get injured or killed by their prey (Mukherjee \& Heithaus, 2013; Kerley, 2018). Therefore, deciding when to attack or avoid potentially dangerous prey is an important aspect of prey selection (Mukherjee \& Heithaus, 2013). Like other carnivore species (Hayward et al., 2006b), African wild dogs seem to take the probability of injury into account by selecting prey species which pose minimal risk of injury 
and avoiding prey species which are likely to stand and defend themselves (Hayward et al., 2006a).

Baboon (Papio spp.) is a prey species which can inflict serious injury and mortality (Cowlishaw, 1994; Estes, 2004) and, where possible, Africa's large carnivores usually avoid predation on baboons (Hayward \& Kerly, 2005; Hayward, 2006; Hayward et al., 2006a, b). Baboons have occasionally been recorded as part of the African wild dog's diet (Woodroffe et al., 2007; Mbizah et al., 2012), however, as far as we are aware, observations of hunts on this prey species have never been described (see also Cowlishaw, 1994; Hayward et al., 2006a). Although baboon lies within their preferred prey body mass range, African wild dogs seem to actively avoid predation on this dangerous prey species (Hayward et al., 2006a). In this study we investigate prey selection patterns of African wild dogs in Mana Pools National Park, Zimbabwe, and discuss which ecological factors are likely to contribute to baboon hunting by African wild dogs.

\section{Method}

\subsection{Study area}

Mana Pools National Park (MPNP) is a $2196 \mathrm{~km}^{2}$ UNESCO Natural World Heritage Site in northern Zimbabwe $\left(15^{\circ} 56^{\prime} \mathrm{S}, 29^{\circ} 27^{\prime} \mathrm{E}\right)$, managed by the Zimbabwe Parks and Wildlife Management Authority. Mean annual rainfall is ca. $706 \mathrm{~mm}$ with a wet season from November to March. July is the coldest month (mean minimum temperature $10.7^{\circ} \mathrm{C}$ ), October the hottest (mean maximum temperature $39.7^{\circ} \mathrm{C}$ ). Four main vegetation types are found in MPNP: Colophospermum mopane woodland, Faidherbia albida woodland, Brachystegia-Julbernardia woodland and Commiphora-Combretum thicket (Figure 1). MPNP is utilised for photographic safaris by vehicle, on foot or by canoe (ZPWMA, 2009).

MPNP is situated along the Zambezi river (Figure 1), which is the main permanent water source for the park. The ecology of MNNP's large mammals is affected by a seasonal dry-season concentration of wildlife on the valley floor due to water availability and the presence of food sources due to prolonged plant productivity and availability of Faidherbia albida on the alluvial floodplains (ZPWMA, 2009). MPNP is home to all species within Africa's large carnivore guild: lion (Panthera leo), spotted hyena (Crocuta crocuta), leopard (Panthera pardus), cheetah (Acinonyx jubatus), 


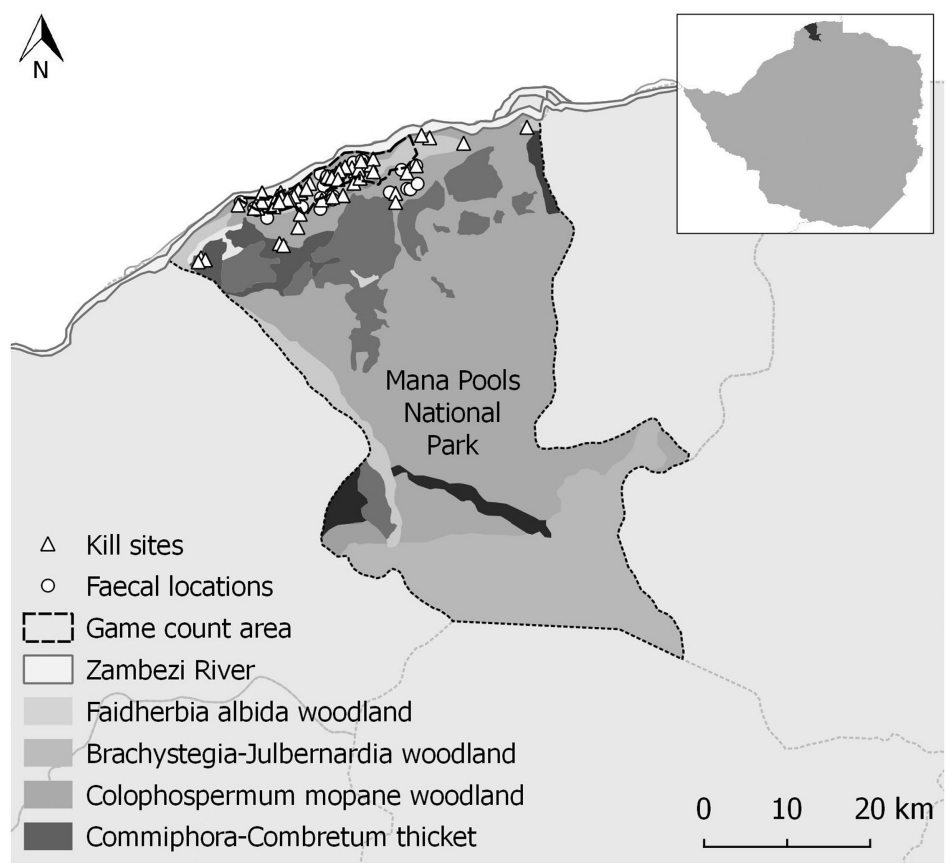

Figure 1. Map of Mana Pools National Park, showing the area along the floodplain of the Zambezi river where data on the two African wild dog study packs, their kills and prey availability were collected.

brown hyena (Parahyaena brunnea) and African wild dog (van der Meer, 2016), and harbours a variety of herbivore species, such as buffalo (Syncerus caffer), eland (Tragelaphus oryx), impala, greater kudu, waterbuck (Kobus ellipsiprymnus) and zebra (Equus quagga). The area is also home to a population of chacma baboons (Papio ursinus) (WEZ, 2017).

\subsection{Direct and indirect observations}

Data from two radio-collared African wild dog packs were collected between 2015 and 2017. These two packs were radio-collared as part of a long-term ongoing ecological study. Target animals (two within each pack) were immobilized for collaring purposes by a qualified license holder (PB), using a Dan-inject dart gun (Dan-inject, Børkop, Denmark) and a drug combination of ketamine/xylazine which was reversed with atipamezole (see Kock \& Burroughs, 2012). A directional antenna was used to locate and keep track of a pack. As soon as a pack was located, continuous observations were 
made from a vehicle for as long as practically feasible. Whether the pack was resting or moving was monitored visually, or from motion sensors in the collars, at 5-min scan intervals. Changes in activity mode or direction were recorded, and location fixes taken by triangulation or visual observations and a GPS unit. The openness of the study area and the extensive road network, which African wild dogs use to travel and rest (Reich, 1981), usually allowed us to keep pace with the pack and follow their (hunting) movements visually and/or by radio-telemetry. When a pack made a kill, we recorded prey species killed and where possible sex and age of the prey species. In addition, we collected sightings from safari guides and operators familiar with the study packs (citizen science observations). In total we recorded 85 direct sightings and 36 citizen science sightings, which resulted in 29 prey records. Because large parts of MPNP are inaccessible during the wet season, direct observations were only made from March untill early December.

In 2015 (end of Feb, June-Dec) and 2016 (March, Aug-Nov) the British Broadcasting Corporation (BBC) joined the research team and followed the two radio-collared packs over a total of 565 days. The BBC made their ca. 320 hours of behavioural video footage available for this study. We analysed the hunt and feeding scenes in the clips and recorded prey species killed and, where possible, sex and age of the prey species. This resulted in an additional 94 prey records.

Mana Pools National Park is well known for allowing unguided game drives and walks, the park annually receives ca. 6000 visitors who are permitted to leave their vehicle and walk anywhere in the park unescorted, in groups or singly (ZPWMA, 2009). Consequently wildlife is habituated to and very relaxed about human presence (ZPWMA, 2009) and the presence of our research team and/or the BBC camera crew is ulikely to have biased the results as presented in this study. The Research Council of Zimbabwe and the Zimbabwe Parks and Wildlife Management Authority provided clearance for this study under permit no23(1) (c) (II) 36/2015: no23(1) (c) (II) 6/2016: no23(1) (c) (II) 3/2017.

\subsection{Faecal samples}

Hairs remain relatively undamaged during digestion; therefore, hairs extracted from carnivore faeces can be used to identify prey species (Keogh, 1983). While following the packs, we opportunistically collected scats $(N=$ 36) whenever we saw an African wild dog defecate. Scats were soaked in 
$4 \%$ formalin for $24 \mathrm{~h}$, washed in a $1.0 \mathrm{~mm}$ mesh sieve under warm running water and sun dried. The samples were examined for prey content by looking at features such as hair length, structure and coloration, and microscopic analysis of cross-sections and cuticle scale imprints of an assortment of six hairs selected from random blocks. We analysed cross-sections from the hairs extracted from the scats by inserting the hairs in a plastic Pasteur pipette. A small amount of beeswax was drawn into the pipette, once the beeswax had set a thin slice (approx. $0.2 \mathrm{~mm}$ ) was sectioned off using a sharp razor blade (Davies-Mostert et al., 2010). In addition, we used cuticular scale imprints (see also Keogh, 1983) by covering a microscope slide with a thin layer of wood glue in which we placed the hairs collected from the scats. Once the glue was air-dried the hairs were gently pulled off the slide and we were left with an imprint of the scale pattern. Prey species were identified by cross referencing cross sections and scale patterns with reference photographs.

\subsection{Analyses}

We used a Pearson's chi-square test to determine whether there was an association between the number of impala and baboon kills recorded for each pack and the data collection method: direct observations, observations from BBC footage and analyses of faecal samples. As we found no significant association (pack I: $\chi^{2}=1.12, p=0.57$, pack II: $\chi^{2}=0.37, p=0.83$ ) prey selection patterns were analysed by combining the three data sets. Duplicate sightings were removed by considering sightings of the same pack, on the same day, within the same time frame, killing the same prey species to be one sighting. Passage rate of food items through the gastrointestinal tract has been predicted to be 24 hours (Davies-Mostert et al., 2010). Faecal samples collected 24 hours after an observation of a kill which contained hair of a species similar to the prey species killed were considered duplicates and removed from the analyses. A total of 153 kills were included in the final analyses (direct observations $(N=29)$, BBC footage $(N=94)$, faecal samples $(N=30))$.

Data on availability of prey species in the area covered by the two African wild dog packs (Figure 1) were obtained from Wildlife and Environment Zimbabwe's annual game counts (WEZ, 2015, 2016, 2017). During these dry season counts experienced game count teams (including a Zimbabwe Parks and Wildlife game ranger) walk across the ca. $45 \mathrm{~km}^{2}$ central Mana 
Pools floodplain (Figure 1) on north-south transect lines which are $500 \mathrm{~m}$ apart and record bird, carnivore and herbivore species within the $250 \mathrm{~m}$ zone on either side of the transect. In two consecutive days, each transect is walked four times: twice in the early morning and twice in the late afternoon (WEZ, 2017). For each year we calculated the proportion of available African wild dog prey species along the floodplain by dividing the mean count of that species (total number counted of a prey species divided by the number of transects) by the sum of the mean count for all prey species (Table 1).

Following Hayward et al. (2006a), we used a Jacobs' index (Jacobs, 1974) to determine whether African wild dogs predated on prey species relative to availability or whether they avoided or preferred certain prey species. The Jacobs' index follows the equation $D=(r-p) /(r+p-2 r p)$, where $r$ is the proportion of prey predated on and $p$ the proportion of prey available. $D$ ranges between -1 (strong avoidance) and +1 (strong preference). In accordance with Hayward et al. (2011), we considered Jacobs' index values between -0.2 and 0.2 as an indication the prey species was predated on as expected based on its availability. Jacobs' index was calculated per pack per year, using the available proportion of prey for a given year. In addition, we calculated the percentages of prey taken within each age and sex class and used a binomial test (test proportion 0.5) to determine whether certain age and sex classes were more often predated on.

Using a genlin procedure, we fitted binary logistic regression models to determine which factors affect the number of baboon kills. Where appropriate we first used a non-parametric, two tailed, point-biserial correlation to test for correlations between variables. Treating impala kills as the reference, we modelled the number of baboon kills in relation to season (wet or dry), breeding season (denning: when pups are too small to follow the pack and the pack returns to the den after foraging, or nomadic: when the pups follow the pack) and time of day the kill was made (unknown, AM or PM). Because pack identity and pack size (number of adults and subadults) were significantly correlated $(r=-0.43, p<0.01)$, only pack identity was included in the models. We considered all possible models without interactions and used Akaike's Information Criterion adjusted for small sample size (AICc) to rank models. Models within 2 AICc units of the best model were considered to have strong support (Burnham \& Anderson, 2002). For each parameter included in the confidence set of models, we computed cumulative 


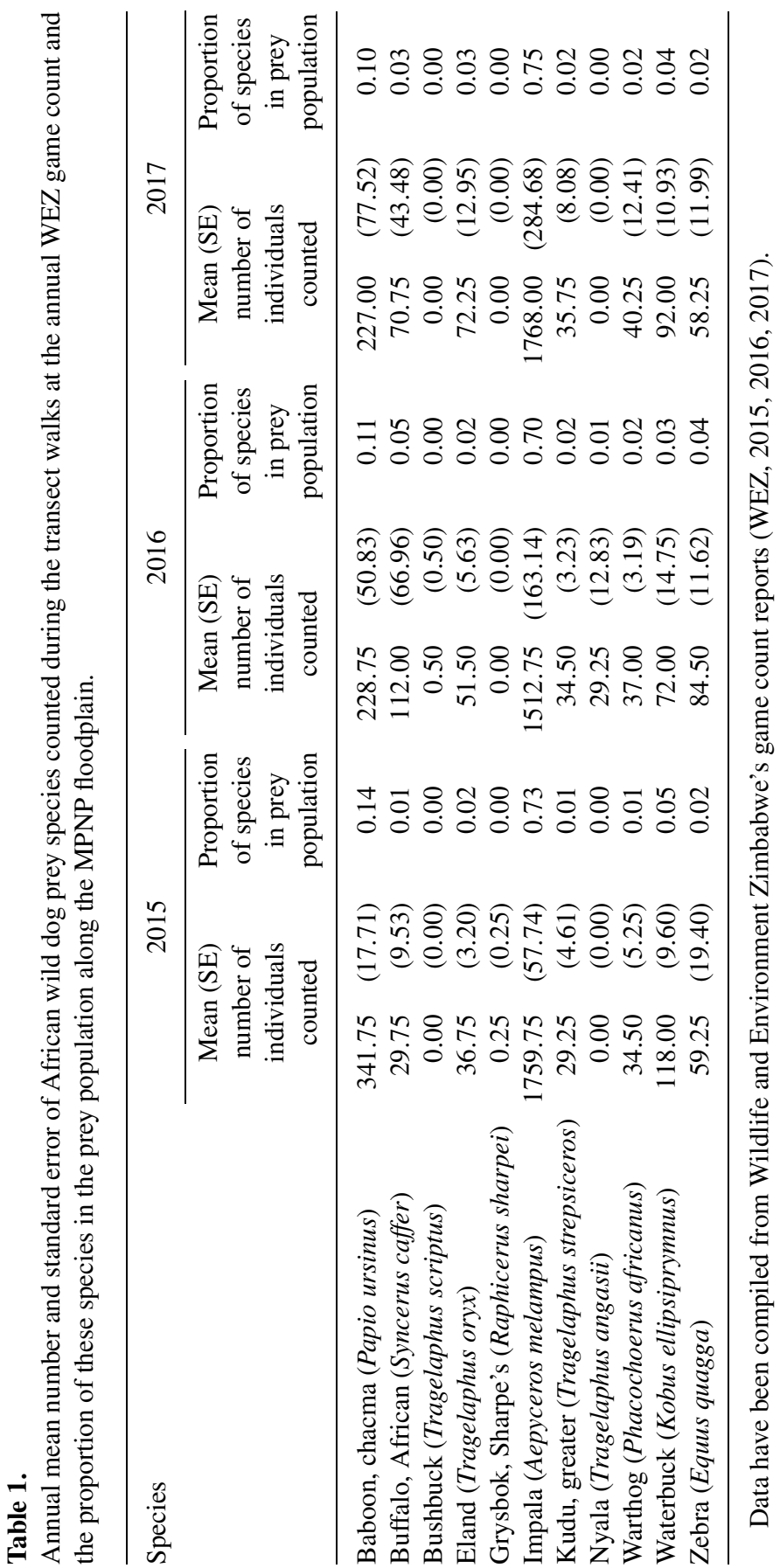


AICc weights $\left(\omega_{i}\right)$ across the models which contained the variable of interest and calculated a model averaged parameter estimate and $85 \%$ confidence intervals (Arnold, 2010) to evaluate its importance (Burnham \& Anderson, 2002; Arnold, 2010). Statistical analyses were performed with SPSS software version 20.0 (SPSS, Chicago, IL, USA).

\section{Results}

We recorded a total of 113 kills by pack I ( $2015 N=32,2016 N=49,2017$ $N=32)$ and 40 kills by pack II $(2015 N=13,2016 N=14,2017 N=13)$. Both study packs predominantly preyed upon impalas and baboons. Pack I was recorded to kill impalas $(N=67)$, baboons $(N=45)$ and a buffalo calf $(N=1)$, pack II to kill impalas $(N=29)$, baboons $(N=8)$ and subadult warthogs $(N=3)$. Throughout the study period, the annual availability of baboons and impalas in the study area remained relatively stable (Table 1). Based on the Jacobs' index calculated per study year, pack I less frequently killed impalas and more frequently killed baboons than expected based on availability (Figure 2a). Pack II predated on impalas relative to availability. Although the pack initially took fewer baboons than expected based on availability (2015), in later years (2016-2017) baboons became a preferred part of the diet (Figure 2b).

The study packs more often predated on adult than subadult impalas $(N=60, p<0.01)$ and took more female than male impalas $(N=56$,

a

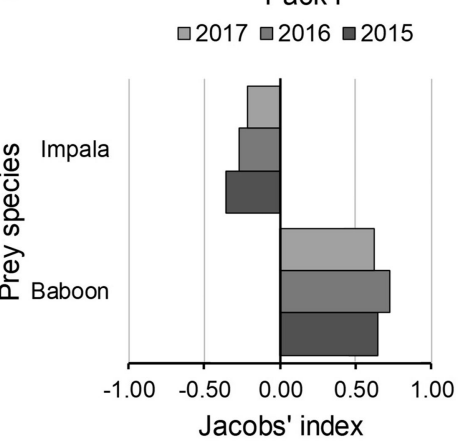

b

Pack II

$\square 2017 \square 2016 \square 2015$

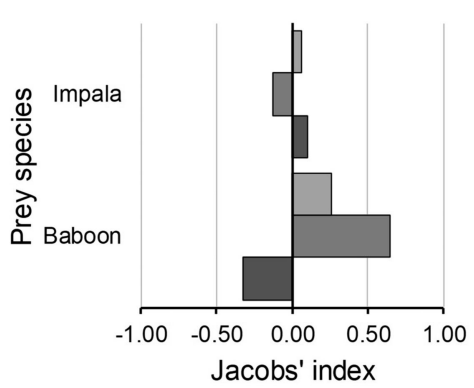

Figure 2. Jacobs' index for prey species predated on by two study packs of African wild dogs in Mana Pools National Park, +1 indicates strong prey preference, -1 indicates strong prey avoidance while values between -0.2 and 0.2 indicate prey is predated on relative to its availability. 

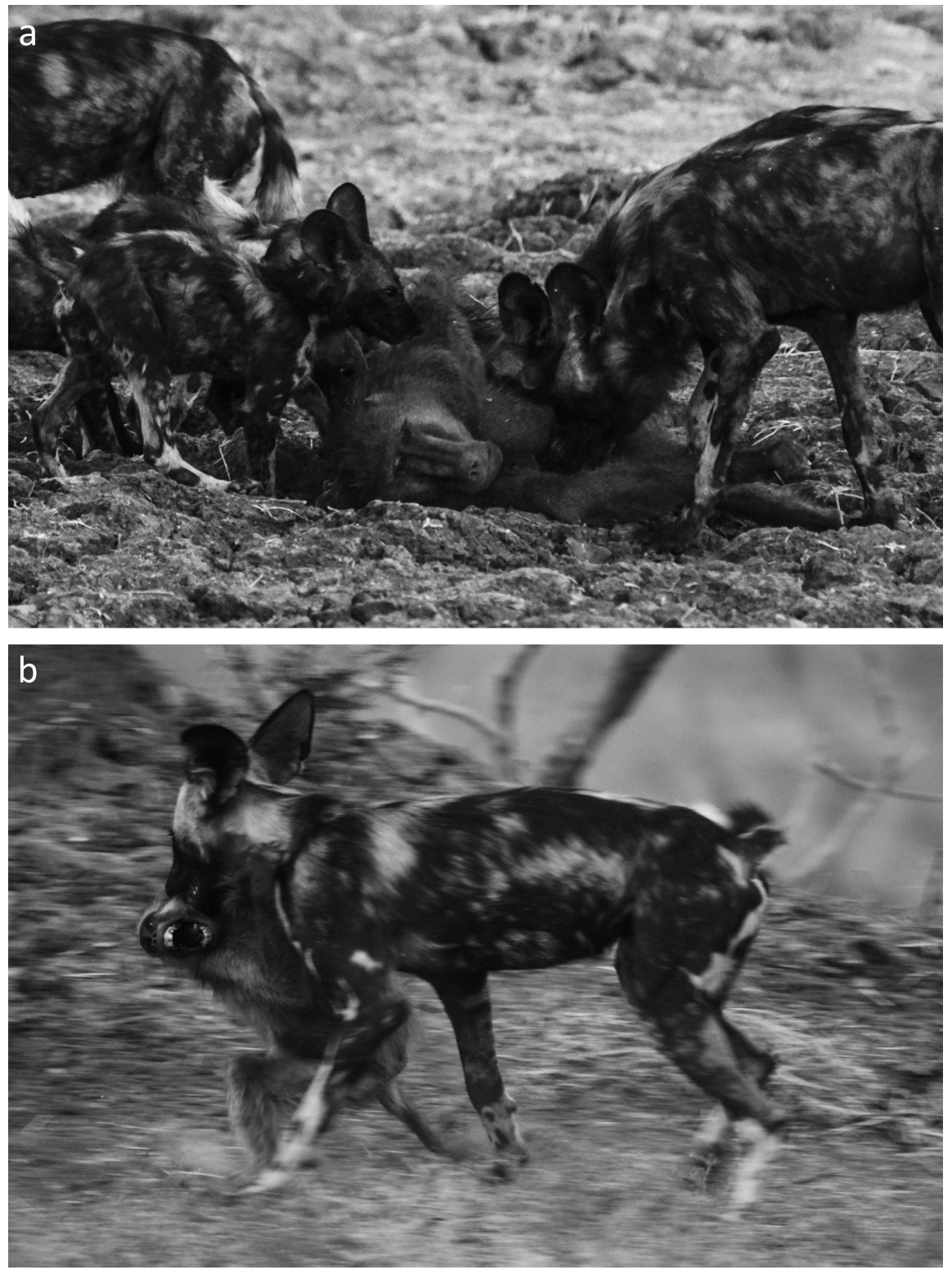

Figure 3. Pack of African wild dogs feeding off adult male baboon kill (a) and African wild dog catching a subadult female baboon (b) Photo credit: BBC. 
Table 2.

Variables, number of parameters in the model $(K)$, Akaike's Information Criterion adjusted for small sample size (AICc), differences in AICc value between the model and the model with the lowest AICc value ( $\triangle \mathrm{AICc})$, AICc weight $\left(\omega_{i}\right)$ and $\log$ likelihood (LL) for models used to predict which factors determine the number of baboon kills.

\begin{tabular}{lccccc}
\hline Model & $K$ & AICc & $\Delta$ AICc & $\omega_{i}$ & LL \\
\hline Season + Breeding season & 3 & 42.52 & 0 & 0.36 & -18.18 \\
Pack identity + Season + Breeding season & 4 & 43.16 & 0.64 & 0.26 & -17.44 \\
\hline
\end{tabular}

Only models with $\triangle \mathrm{AICc} \leqslant 2$ are presented.

$p<0.01)$. Where impala age and sex could be determined $(N=60)$, adult females $(61.7 \%)$ outnumbered adult males $(21.7 \%)$, followed by juveniles $(6.7 \%)$ and subadult males $(5.0 \%)$ and females $(5.0 \%)$. The study packs predated as often on adult as on subadult baboons $(N=34, p=1.00)$, and did not take significantly more male than female baboons $(N=10, p=0.75)$. Where baboon age and sex could be determined $(N=9)$, five were adult males (Figure 3a), three were adult females and one was a subadult female (Figure 3b). Nine adults, 16 subadults and two juveniles were of unknown sex.

The parameter time of day the kill was made did not occur in the confidence set of models and was therefore considered not to have a substantial impact on the number of baboon kills. Based on the models with the most support (Table 2), the relative importance of individual parameters (Table 3) and taking into account $85 \%$ confidence intervals of the model averaged parameter estimates, the number of baboon kills was higher in the dry sea-

\section{Table 3.}

Model averaged parameter estimates $(\beta)$, standard errors (SE), 85\% confidence intervals (CI) (see Arnold, 2010) and Akaike importance weights $\left(\sum \omega_{i}\right)$ for the parameters in the highest ranking models $(\triangle \mathrm{AICc} \leqslant 2)$ used to predict which factors determine the number of baboon kills.

\begin{tabular}{lrrrrrr}
\hline Model parameter & $\beta$ & SE & \multicolumn{2}{c}{$85 \%$ CI } & $\sum \omega_{i}$ \\
\cline { 5 - 6 } & & & Lower & Upper & \\
\hline Intercept & -1.93 & 0.64 & -2.84 & -1.01 & 1.00 \\
Season: Dry (Wet = reference) & 1.80 & 0.54 & 1.02 & 2.58 & 0.99 \\
Breeding season: Denning (Nomadic = reference) & -1.01 & 0.49 & -1.72 & -0.29 & 0.78 \\
Pack ID: Pack I (Pack II = reference) & 0.56 & 0.47 & -0.12 & 1.24 & 0.42 \\
\hline
\end{tabular}


son than the wet season and lower in the denning season than the nomadic season. Model averaged $85 \%$ confidence intervals for the parameter pack identity included zero (Table 3), this parameter was therefore discarded as an uninformative parameter (Arnold, 2010). During the study period, pack size (adults and subadults) varied considerably (Table A1 in the Appendix) with an overall average pack size of $16.0 \pm 1.5$ (mean \pm SE) adults and subadults for pack I and $10.9 \pm 0.4$ (mean \pm SE) adults and subadults for pack II. The point-biserial correlation confirmed there was no significant relationship between pack size and the number of impalas or baboons killed $(r=-0.04, p=0.60)$.

Direct observations $(N=29)$ showed spotted hyenas were present at $20.7 \%$ of the kills (four impala kills, one baboon kill and a kill of a buffalo calf). However, losses to kleptoparasitism were little as spotted hyenas generally only arrived after the African wild dogs were close to finishing or had finished feeding from their kill.

\section{Discussion}

Although the line transect method is a flexible and cheap method to estimate the abundance of wildlife species, it has its shortcomings (Greene, 2012). Especially when, like in this study, limitations of the data set prevent the use of distance sampling software to account for variation in detectability. Besides, because this method assumes all animals are detected at their initial location, animal movement can create bias, particularly when animals move in response to the observers (Palka \& Hammond, 2001; Glennie et al., 2015). As a result of allowing unguided walks, the wildlife in MPNP is exceptionally relaxed about human presence. In addition, the floodplain consists of very open vegetation which facilitates easy detection of wildlife. Counting bias due to differences in detection ability or animal movement is therefore minimal. Game counts took place in the dry season in an area containing the main permanent water source of MPNP. Although less so for browers, distribution patterns of grazers are strongly affected by water availability (Redfern et al., 2003). The game count data set is therefore unlikely to be representative for prey abundance in MPNP as a whole. However, because the area sampled is representative for the area utilised by the African wild dog study 
packs (Figure 1) we do feel the game count data provides a reliable indication of relative prey availability which can be used to draw conclusions about prey selection of the two study packs.

The African wild dog packs in our study predominantly predated on impalas and baboons. Compared to impalas, which present limited threat of injury to predators (Hayward et al., 2006a, b), baboons, a prey species for which adult males especially are known to retaliate against predators, present a high risk of injury (Cowlishaw, 1994; Estes, 2004). It is challenging to accurately assess frequency of injury from dangerous prey (Mukherjee \& Heithaus, 2013) and our data on frequency of baboon related injuries are limited. However, we observed several cases in which baboons defended themselves, their young, or other troop members against African wild dog attacks (Figure 4) and baboon hunts did result in injury (Figure 5). Injury is an important foraging cost (Mukherjee \& Heithaus, 2013) which predators take into account by avoiding prey which presents a high risk of injury or mortality (Hayward et al., 2006a, b). However, in this study, once included in the diet, the African wild dog study packs preferred to predate on baboons.

Prey vulnerability to predation varies over age and sex classes (Cowlishaw, 1994; Pole et al., 2004) and is affected by season (Pole et al., 2004). While some studies describe adult male baboons to be most vulnerable to predation (Cowlishaw, 1994), others only found age differences in vulnerability (adults more vulnerable than subadults) (Jooste et al., 2012). The African wild dog packs in this study predated equally on male and female and adult and subadult baboons. Vulnerability of impala sex and age classes of to African wild dog predation is affected by sex ratio and season (Reich, 1981; Pole et al., 2004). In some ecosystems, overall predation is higher on adults males (Pole et al., 2004) while in other ecosystems female and adult impalas are more vulnerable to African wild dog predation (Reich, 1981; Vogel et al., 2018). Compared to males and subadults, our study packs predated more heavily on female and adult impalas. Predation on impalas increased in the wet season, baboon predation was higher in the dry season. Baboons do not have a demarcated breeding season (Cheney et al., 2004) but impalas give birth to their fawns in the wet season (Child, 1964). During this period, pregnancy and lactations reduces fat reserves of female impalas to a minimum (Pole et al., 2004). African wild dogs select young prey animals or prey in poor body condition (Fitzgibbon \& Fanshawe, 1989; Pole et al., 2004) and the wet season provides an abundance of out of condition impala females and 

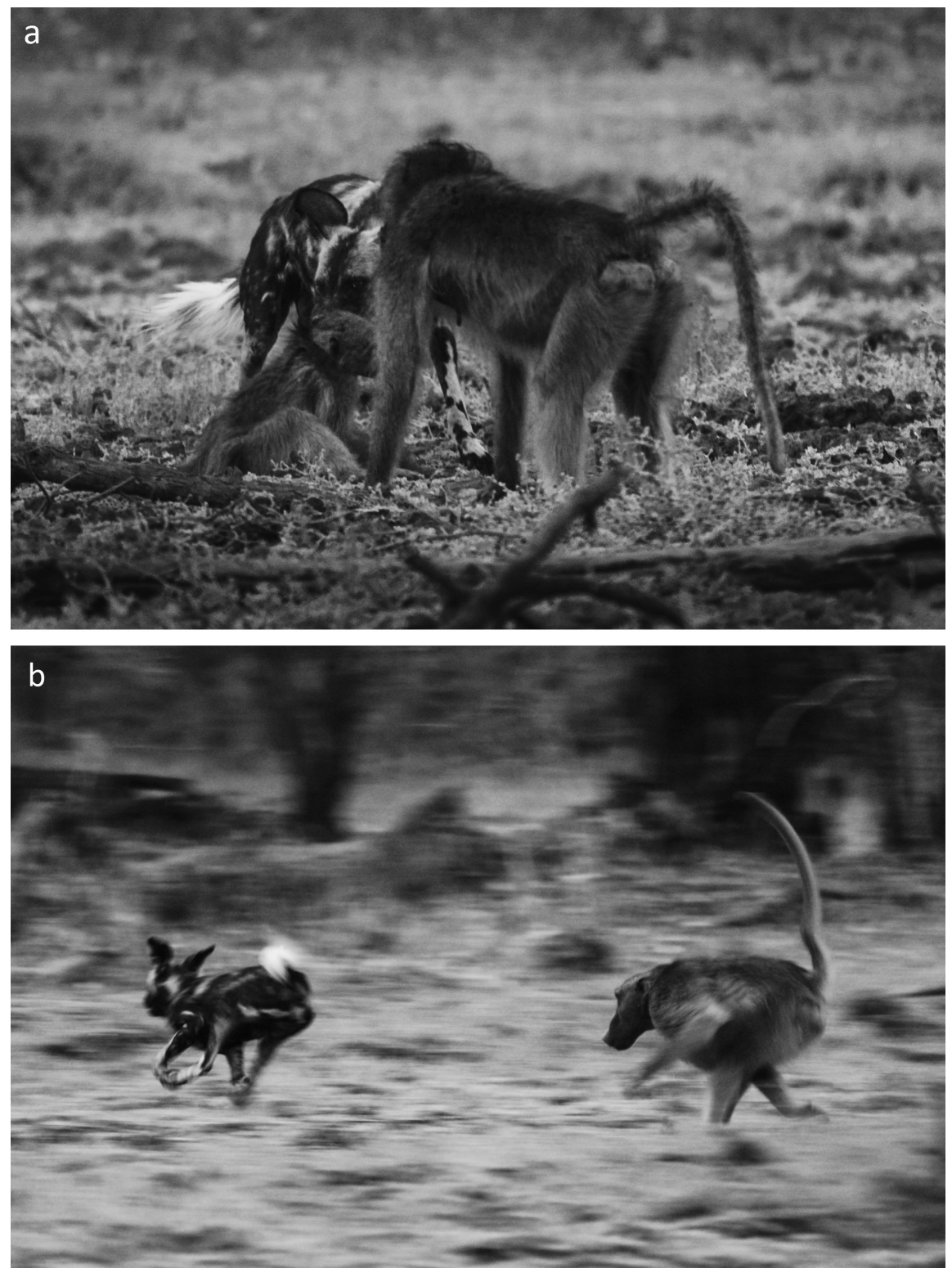

Figure 4. Stand-off between female baboon and African wild dog which attempts to predate on a juvenile baboon (a) and adult male baboon chasing African wild dog (b). Photo credit: BBC. 

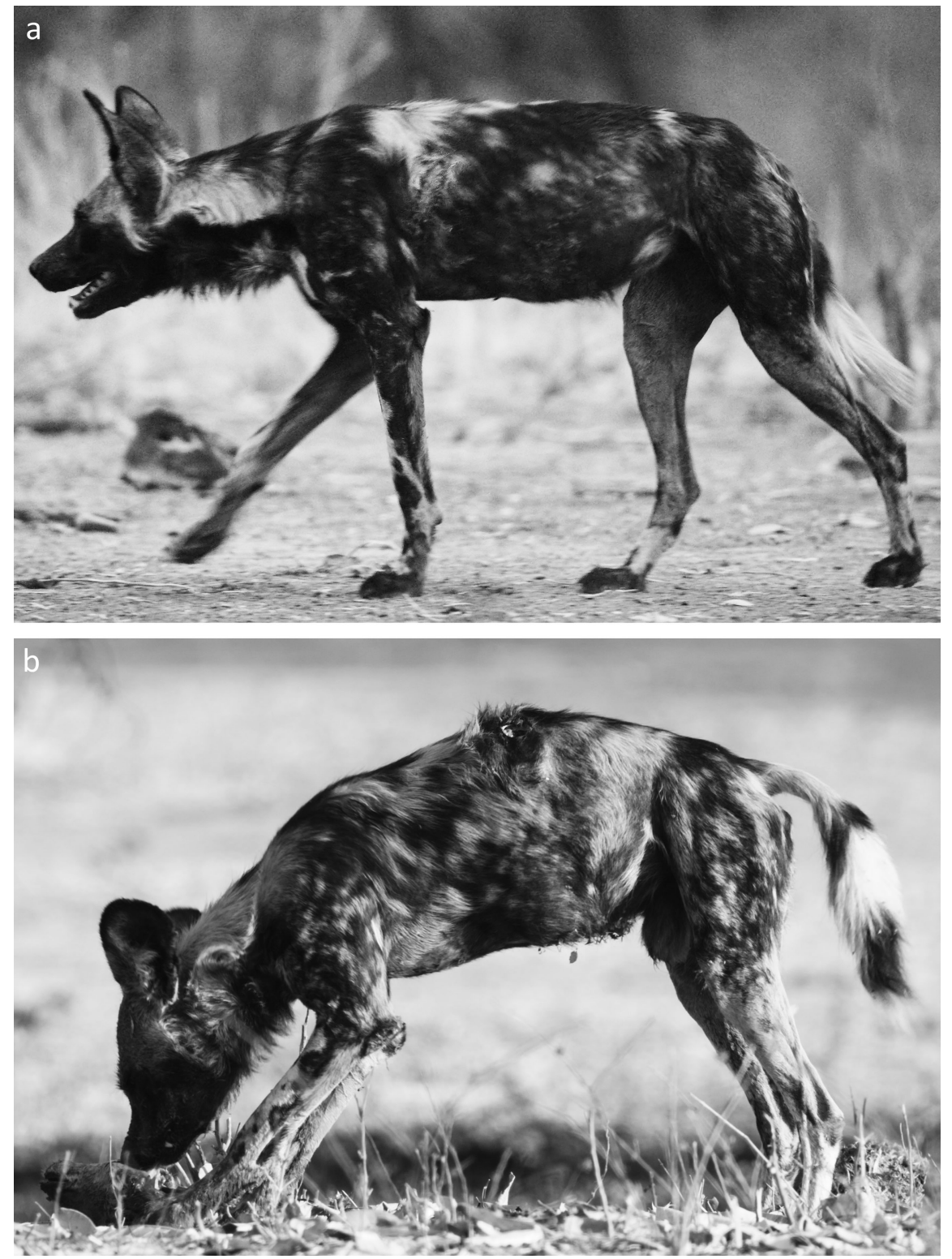

Figure 5. African wild dog with baboon injury on left flank (a) and African wild dog with baboon injury on its back (b). Photo credit: BBC. 
young and naïve impalas that are relatively easy to catch (Pole et al., 2004). In addition, extensive elephant movement along the muddy floodplain of MPNP results in a rugged surface of hardened, dried out, elephant footprints in the dry season, herewith increasing the difficulty of high speed pursuits of impalas and the indirect risk of injury such pursuits present (Mukherjee \& Heithaus, 2013).

Baboon kills were less frequently made in the denning season when the need to feed the pups at the den can affect prey selection (Woodroffe et al., 2007). Body mass of adult impalas (adult male ca. $60 \mathrm{~kg}$, adult female ca. $45 \mathrm{~kg}$ ) is 2-3 times higher than body mass of adult baboons (adult male ca. $32 \mathrm{~kg}$, adult female ca. $15.4 \mathrm{~kg}$ ) of the same sex (Estes, 2004), a baboon kill is therefore less likely to feed the entire pack. Although African wild dogs generally consume $2-3 \mathrm{~kg}$ of meat per individual (Creel \& Creel, 1995; Carbone et al., 2007), stomach capacity is ca. $9 \mathrm{~kg}$ (Creel \& Creel, 1995). Consequently, predation on impalas maximizes food intake of the pack and herewith the quantity of meat which can be regurgitated for the pups upon return to the den. With larger packs being able to kill larger prey (Creel $\&$ Creel, 2002), a preference for smaller prey could be an indication of suboptimal pack sizes. However, in accordance with Woodroffe et al. (2007), we found no evidence pack size (adults + subadults) affected predation on baboons or impalas. Throughout the study, pack size of our African wild dog study packs was $\geqslant 7$ adults, which is considered a viable pack size for cooperative hunting and breeding (Courchamp et al., 2002). Therefore, an inability to secure larger prey due to suboptimal pack sizes does not explain why African wild dogs in MPNP preferentially predated on baboons.

Preferential predation on baboons also does not seem to be the result of a low availability of impalas. There are many ecosystems where impalas are the principal prey species of African wild dogs, compared to these systems, impala densities along the MPNP floodplain $\left(37.3 / \mathrm{km}^{2}\right)$ are relatively high (e.g., Selous 28.6/ $\mathrm{km}^{2}$, Savé 11.7/ $/ \mathrm{km}^{2}$ ) (Creel \& Creel, 2002; Pole et al., 2004). Apart from the presence of prey, prey selection may also be affected by the presence of larger competitors: the risk of encountering larger competitors increases with handling time of the kill, which is shorter for smaller prey items (Hamilton, 2002). However, compared to other ecosystems (presence larger competitors at kill sites 9-86\%, kleptoparasitism 0-100\%), kleptoparasitism and presence of larger competitors at kill sites of African wild dogs was not exceptionally high (Creel \& Creel, 1998; van der Meer et al., 
2011); therefore, interspecific competition alone does not seem to explain prey selection by the MPNP study packs.

Profitability of prey is related to energy content but also to energy spend finding, pursuing and subduing prey (Creel \& Creel, 2002). Like in other ecosystems, along the MPNP floodplain impalas and baboons have formed interspecific associations to optimise feeding and anti-predator strategies (Davis \& Ebersole, 2015). Consequently, search efficiency for impalas and baboons are likely to be similar; however, chase distance may differ substantially. When encountering a predator, impalas are quick to take flight, while baboons, when foraging on the ground during daytime, seek refuge in the nearest tree and when necessary confront a predator (Cowlishaw, 1997; Estes, 2004). The MPNP floodplain consists of open woodland with little understory in which it is relatively easy to detect approaching predators and difficult to find refuge. Such open habitat increases flight initiation distance (Stankowich \& Blumstein, 2005) which increases the distance over which prey is chased by African wild dogs (Reich, 1981) and the likelihood of a kill (Creel \& Creel, 2002). Where impalas are known for their manoeuvrability and high speed (ca. $50 \mathrm{~km} / \mathrm{h}$ ) when escaping predation (Wilson et al., 2018), baboons are much slower. In this study, baboons were always chased over short distances $(<100 \mathrm{~m})$ and, unlike impala hunts, baboon hunts would normally result in the pack outrunning and killing at least one individual in the troop before it found refuge. Such differences in hunting efficiency can outweigh a lower energy intake and enable African wild dogs to subsist on smaller prey species (Woodroffe et al., 2007).

As far as we are aware, this is the first study which describes preferential predation of African wild dogs on baboons (see also Cowlishaw, 1994; Hayward et al., 2006a). Hunting dangerous prey like baboons requires skills which vary among individuals (Jooste et al., 2013). Baboon hunting in MPNP is believed to have started with the original alpha female of pack I, which was first witnessed to hunt baboons about a decade ago (personal communication safari operators). Both study packs consist of offspring of this female. Although pack II initially avoided baboon predation, once seven dispersers of pack I joined the pack in December 2015, baboons became a preferred part of the diet. In addition to these two study packs, there are five known African wild dog packs in MPNP, only one of these other packs has ever been witnessed to predate on baboons (personal communication safari operators), this pack was formed mid 2017 and consists of four individuals of which two are dispersers from pack I. In accordance with Jooste et al. (2013), 
these observations suggest predation on baboons may be an individually acquired pattern of behaviour which disseminates through the MPNP African wild dog study packs via social learning (acquiring new behaviour by observing and imitating others, see Galef, 1976). However, further research will be necessary to confirm this hypothesis and to gain a more detailed insight in the various factors likely to affect the MPNP study packs' unusual prey preference for baboons.

\section{Acknowledgements}

We would like to thank M. Hayward, G. Mills, D. Parker and an anonymous reviewer for critically reading the manuscript and suggesting substantial improvements. We thank the Research Council of Zimbabwe and the Zimbabwe Parks and Wildlife Management Authority for providing the necessary permits to carry out this research. We would like to express our gratitude to H. Madzikanda, F. Nsingo, N. Murray, H. Bandure, S. Josia, W. Sloss, B. Britton, J. Evans, R. Steinmann and M. Yates for their (logistic) support and assistance with the data collection. We also thank C. Sibanda, S. Phiri, G. Njamba and T. Tauro for their assistance with the faecal analyses.

\section{References}

Arnold, T.W. (2010). Uninformative parameters and model selection using Akaike's information criterion. - J. Wildl. Manag. 74: 1175-1178.

Burnham, K.P. \& Anderson, D.R. (2002). Model selection and inference: a practical information-theoretic approach. - Springer, New York, NY.

Carbone, C., Mace, G.M., Roberts, S.C. \& Macdonald, D.W. (1999). Energetic constraints on the diet of terrestrial carnivores. - Nature 402: 286-288.

Carbone, C., Teacher, A. \& Rowcliffe, J.M. (2007). The costs of carnivory. — PLOS Biol. 5: e22. DOI:10.1371/journal.pbio.0050022.

Cheney, D.L., Seyfarth, R.M., Fischer, J., Beehner, J.C., Bergman, T.J., Johnson, S.E., Kitchen, D.M., Palombit, R.A., Rendall, D. \& Silk, J.B. (2004). Factors affecting reproduction and mortality among baboons in the Okavango Delta, Botswana. - Int. J. Primatol. 25: 401-428.

Child, G. (1964). Growth and ageing criteria of impala Aepyceros melampus. — Occas. Pap. Natl Mus. South. Rhod. 4: 128-135.

Courchamp, F., Rasmussen, G.S.A. \& Macdonald, D.W. (2002). Small pack size imposes a trade-off between hunting and pup-guarding in the painted hunting dog Lycaon pictus. Behav. Ecol. 13: 20-27.

Cowlishaw, G. (1994). Vulnerability to predation in baboon populations. - Behaviour 131: 293-304. 
Cowlishaw, G. (1997). Refuge use and predation risk in a desert baboon population. - Anim. Behav. 54: 241-253.

Creel, S. \& Creel, N.M. (1995). Communal hunting and pack size in African wild dogs, Lycaon pictus. - Anim. Behav. 50: 1325-1339.

Creel, S. \& Creel, N.M. (1998). Six ecological factors that might limit African wild dogs. Anim. Conserv. 1: 1-9.

Creel, S. \& Creel, N.M. (2002). The African wild dog: behavior, ecology, and conservation. - Princeton University Press, Princeton, NJ.

Davies-Mostert, H.T., Mills, M.G.L., Kent, V. \& Macdonald, D.W. (2010). Reducing potential sources of sampling bias when quantifying the diet of the African wild dog through scat analysis. - S. Afr. J. Wildl. Res. 40: 105-113.

Davis, B.R. \& Ebersole, J.J. (2015). Impala (Aepyceros melampus) associate with olive baboons (Papio anubis) for feeding and security in Tarangire National Park, Tanzania. Afr. J. Ecol. 54: 238-241.

Estes, R.D. (2004). The behavior guide to African mammals: including hoofed mammals, carnivores, primates, 4th edn. - University of California Press, Berkeley, CA.

Estes, R.D. \& Goddard, J. (1967). Prey selection and hunting behavior of the African wild dog. - J. Wildl. Manage. 31: 52-70.

Fitzgibbon, C.D. \& Fanshawe, J.H. (1989). The condition and age of Thompson's gazelles killed by cheetah and wild dog. - J. Zool. 218: 99-107.

Galef, B.G. (1976). Social transmission of acquired behavior: a discussion of tradition and social learning in vertebrates. - Adv. Stud. Behav. 3: 77-100.

Glennie, R., Buckland, S.T. \& Thomas, L. (2015). The effect of animal movement on line transect estimates of abundance. — PLoS ONE 10: e0121333. DOI:10.1371/journal.pone. 0121333.

Greene, T. (2012). Birds incomplete counts - line transect counts, version 1.0. - Department of Conservation, Wellington.

Hamilton, I.M. (2002). Kleptoparasitism and the distribution of unequal competitors. Behav. Ecol. 13: 260-267.

Hayward, M.W. (2006). Prey preferences of the spotted hyaena (Crocuta crocuta) and degree of dietary overlap with the lion (Panthera leo). - J. Zool. 270: 606-614.

Hayward, M.W. \& Kerley, G.I.H. (2005). Prey preferences of the lion (Panthera leo). J. Zool. 267: 309-322.

Hayward, M.W., O’Brien, J., Hofmeyr, M. \& Kerley, G.I.H. (2006a). Prey preferences of the African wild dog Lycaon pictus (Canidae: Carnivora): ecological requirements for conservation. — J. Mammal. 87: 1122-1131.

Hayward, M.W., Henschel, P., O’Brien, J., Hofmeyr, M., Balme, G. \& Kerley, G.I.H. (2006b). Prey preferences of the leopard (Panthera pardus). - J. Zool. 270: 298-313.

Hayward, M.W., Hayward, G.J., Tambling, C.J. \& Kerley, G.I.H. (2011). Do lions Panthera leo actively select prey or do prey preferences simply reflect chance responses via evolutionary adaptations to optimal foraging? — PLoS ONE 6: e23607. DOI:10.1371/journal. pone. 0023607. 
Hubel, T.Y., Myatt, J.P., Jordan, N.R., Dewhirst, O.P., McNutt, J.W. \& Wilson, A.M. (2016). Additive opportunistic capture explains group hunting benefits in African wild dogs. Nature Commun. 7: 11033. DOI:10.1038/ncomms11033.

Jacobs, J. (1974). Quantitative measurement of food selection: a modification of the forage ratio and Ivlev's electivity index. - Oecologia 14: 413-417.

Jooste, E., Pitman, R.T., van Hoven, W. \& Swanepoel, L.H. (2012). Unusually high predation on Chacma baboons (Papio ursinus) by female leopards (Panthera pardus) in the Waterberg Mountains, South Africa. - Folia Primatol. 83: 353-360.

Keogh, H.J. (1983). A photographic reference system of the microstructure of the hairs of southern African bovids. - S. Afr. J. Wildl. Res. 13: 89-131.

Kerley, G.I.H. (2018). Dying for dinner: a cheetah killed by a common duiker illustrates the risk of small prey to predators. — Afr. J. Wildl. Res. 48: 024001. DOI:10.3957/056.048. 024001 .

Kock, M.D. \& Burroughs, R. (2012). Chemical and physical restraint of wild animals, a training field manual for African species, 2nd edn. - International Wildlife Veterinary Services, Greyton.

Mbizah, M.M., Marino, J. \& Groom, R.J. (2012). Diet of four sympatric carnivores in Savé Valley Conservancy, Zimbabwe: implications for conservation of the African wild dog (Lycaon pictus). — S. Afr. J. Wildl. Res. 42: 94-103.

Mukherjee, S. \& Heithaus, M.R. (2013). Dangerous prey and daring predators: a review. Biol. Rev. 88: 550-563.

Palka, D.L. \& Hammond, P.S. (2001). Accounting for responsive movement in line transect estimates of abundance. — Can. J. Fish. Aquat. Sci. 58: 777-787.

Pole, A., Gordon, I.J., Gorman, M.L. \& MacAskill, M. (2004). Prey selection by African wild dogs (Lycaon pictus) in southern Zimbabwe. - J. Zool. 262: 207-215.

Radloff, F.G.T. \& du Toit, J. (2004). Large predators and their size in a southern African savanna: a predator's size determines its prey range. - J. Anim. Ecol. 73: 410-423.

Redfern, J.V., Grant, R., Biggs, H. \& Getz, W.M. (2003). Surface-water constraints on herbivore foraging in the Kruger National Park, South Africa. — Ecology 84: 2092-2107.

Reich, A. (1981). The behaviour and ecology of the African wild dog Lycaon pictus in the Kruger National Park. - Doctorate thesis. Yale University, New Haven, CT.

Stankowich, T. \& Blumstein, D.T. (2005). Fear in animals: a meta-analysis and review of risk assessment. — Proc. Roy. Soc. Lond. B: Biol. Sci. 272: 2627-2634.

Van der Meer, E., Moyo, M., Rasmussen, G.S.A. \& Fritz, H. (2011). An empirical and experimental test of risk and cots of kleptoparasitism for African wild dogs (Lycaon pictus) inside and outside a protected area. — Behav. Ecol. 2: 985-992.

Van der Meer, E. (2016). The cheetahs of Zimbabwe - distribution and population status 2015. - CCPZ, Victoria Falls. DOI:10.13140/RG.2.2.36719.84648. Available from cheetahzimbabwe.org [Last accessed 10 October 2018].

Vogel, J.T., Somers, M.J. \& Venter, J.A. (2018). The foraging ecology of reintroduced African wild dog in small protected areas. - Wildl. Biol. 2018: 00424. DOI:10.2981/wlb.00424.

WEZ (2015). Mana Pools game count 2015. — Wildlife and Environment Zimbabwe, Harare. WEZ (2016). Mana Pools game count 2016. — Wildlife and Environment Zimbabwe, Harare. 
WEZ (2017). Mana Pools game count 2017. — Wildlife and Environment Zimbabwe, Harare. Wilson, A.M., Hubel, T.Y., Wilshin, S.D., Lowe, J.C., Lorenc, M., Dewhirst, O.P., BartlamBrooks, H.L.A., Diack, R., Bennitt, E., Golabek, K.A., Woledge, R.C., McNutt, J.W., Curtin, N.A. \& West, T.G. (2018). Biomechanics of predator-prey arms race in lion, zebra, cheetah and impala. - Nature 554: 183-188.

Woodroffe, R., Lindsey, P.A., Romanãch, S. \& Ole Ranah, S.M.K. (2007). African wild dogs (Lycaon pictus) can subsist on small prey: implications for conservation. - J.Mammal. 88: 181-193.

ZPWMA (2009). Mana pools national park general management plan 2009-2019. — Zimbabwe Parks and Wildlife Management Authority, Harare.

\section{Appendix}

Table A1.

Annual pack composition described as the number of adults plus subadults and pups (mean \pm SE) of pack I and pack II during the study period 2015-2017.

\begin{tabular}{|c|c|c|c|c|c|}
\hline \multirow[t]{2}{*}{ Pack } & \multicolumn{2}{|c|}{ Adults + subadults } & \multicolumn{2}{|c|}{ Pups } & \multirow[t]{2}{*}{ History } \\
\hline & Mean & SE & Mean & SE & \\
\hline \multicolumn{6}{|l|}{ Pack I } \\
\hline 2015 & 19.2 & 2.6 & 3.7 & 0.5 & $\begin{array}{l}\text { The pack started the year with } 30 \text { adults and } \\
\text { subadults. Two groups of five individuals } \\
\text { dispersed early in the breeding season, one group } \\
\text { of seven males dispersed at the end of } 2015 \text {. One } \\
\text { individual died, three went missing. Five pups } \\
\text { emerged from the den, one was killed by lion, one } \\
\text { by spotted hyena. }\end{array}$ \\
\hline 2016 & 11.0 & 0.6 & 9.5 & 0.6 & $\begin{array}{l}\text { The pack started the year with } 12 \text { adults and } \\
\text { subadults. In October one individual got killed by } \\
\text { a crocodile while drinking at a waterhole. Eleven } \\
\text { pups emerged from the den, one died, one was } \\
\text { killed by spotted hyena, three went missing, six } \\
\text { survived. }\end{array}$ \\
\hline 2017 & 15.0 & 0.8 & 9.3 & 1.1 & $\begin{array}{l}\text { The pack started the year with } 17 \text { adults and } \\
\text { subadults. One individual was killed by lion, two } \\
\text { went missing, two adults dispersed to form the } \\
\text { Ruckometchi pack. Twelve pups emerged from } \\
\text { the den, two were killed by leopard, two by } \\
\text { spotted hyena, one by lion. The pack ended the } \\
\text { year with } 12 \text { adults and subadults and seven pups. }\end{array}$ \\
\hline Total & 16.0 & 1.5 & 7.4 & 1.0 & \\
\hline
\end{tabular}




\section{Table A1.}

(Continued.)

\begin{tabular}{|c|c|c|c|c|c|}
\hline \multirow[t]{2}{*}{ Pack } & \multicolumn{2}{|c|}{ Adults + subadults } & \multicolumn{2}{|c|}{ Pups } & \multirow[t]{2}{*}{ History } \\
\hline & Mean & SE & Mean & SE & \\
\hline \multicolumn{6}{|l|}{ Pack II } \\
\hline 2015 & 11.7 & 0.6 & 2.0 & 0.0 & $\begin{array}{l}\text { The pack started the year with } 11 \text { adults and } \\
\text { subadults. Two pups emerged from the den but } \\
\text { died. Towards the end of the year four individuals } \\
\text { went missing and the remaining seven females } \\
\text { were joined by seven dispersing males of pack I. }\end{array}$ \\
\hline 2016 & 10.0 & 0.0 & 3.0 & 1.0 & $\begin{array}{l}\text { The pack started the year with } 14 \text { adults and } \\
\text { subadults One adult died, three went missing. } \\
\text { Five pups emerged from the den, one was killed } \\
\text { by lions, three went missing. }\end{array}$ \\
\hline 2017 & 9.8 & 0.4 & 1.6 & 0.9 & $\begin{array}{l}\text { The pack started with } 11 \text { adults and subadults. } \\
\text { Two individuals went missing. Five pups emerged } \\
\text { from the den, one got killed by hyena, four went } \\
\text { missing. The pack ended the year with nine adults } \\
\text { and subadults. }\end{array}$ \\
\hline Total & 10.9 & 0.4 & 2.0 & 0.5 & \\
\hline
\end{tabular}

